\title{
The Relative Importance Sector and Regional Factors in Italy
}

\author{
A Paper Presented at the $12^{\text {th }}$ Annual \\ European Real Estate Society (ERES) Meeting \\ Dublin, June 2005
}

\begin{abstract}
Stephen Lee* and Laura Gabrielli **
*The University of Reading Business School, Centre for Real Estate Research (CRER), The University of Reading, Reading, RG6 6AW, England
\end{abstract}

\author{
Phone: +44 118378 6338, Fax: +44 118378 8172, E-mail: S.L.Lee@reading.ac.uk \\ **Iuav - University of Architecture of Venice, Planning Department \\ Dorsoduro, 2206, 30123 Venice, Italy \\ Phone: +39 041257 1387, Fax +39 041257 1393, E-mail: gabriel@brezza.iuav.it
}

\begin{abstract}
The benefits of sector and regional diversification have been well documented in the literature but have not previously been investigated in Italy. In addition, previous studies have used geographically defined regions, rather than economically functional areas, when performing the analysis even though most would argue that it is the economic structure of the area that will lead to differences in demand and hence property performance. This study therefore uses economically defined regions of Italy to test the relative benefits of regional diversification versus sector diversification within the Italian real estate portfolio. To examine this issue we use constrained cross-section regressions the on the sector and regional affiliation of 14 cities in Italy to extract the "pure" return effects of the different factors using annual data over the period 1989 to 2003. In contrast, to previous studies we find that regional factors effects in Italy have a much greater influence on property returns than sectorspecific effects, which is probably a direct result of using the extremely diverse economic regions of Italy rather than arbitrary geographically locations. Be that as it may, the results strongly suggest that that diversification across the regions of Italy used here is likely to offer larger risk reduction benefits than a sector diversification strategy within a region. In other words, fund managers in Italy must monitor the regional composition of their portfolios more closely than its sector allocation. Additionally, the results supports that contemporary position that 'regional areas' based on economic function, provide greater diversification benefits rather than areas defined by geographical location.
\end{abstract}

Keywords: Real estate returns, sector and regional effects, dummy variable regressions 


\section{The Relative Importance of Sector and Regional Factors in Italy}

\section{Introduction}

The relative benefit of sector and regional diversification is a topic of continuing interest to academics. In order to examine this issue most studies have used the dummy variable methodology of Heston and Rouwenhorst (HR) (1994). In this approach the returns of real estate are assigned variables that identify its sector and regional affiliation. Thus, when these dummy variables were regressed on the cross-section of property returns, the estimated coefficients on the dummy variables are the implicit, or "pure", return effects of the different factors. The majority of work concluding that sector (property-type) diversification is preferable to regional (geographical) diversification in terms of risk reduction.

For instance, Fisher and Liang (2000) used the dummy variable approach to decompose the returns of US real estate into 4 sectors and 4 regions. Using quarterly returns from the NCREIF database over the period 1978:Q1 to 1999:Q4 the authors found that the average cross-correlation of the pure sector indices was lower than the average cross-correlation of the regional effects. In addition, the pure sector indices had higher tracking errors than the pure regional indices. Both results suggest that sector diversification is more effective than regional diversification. Lee (2001) used the total returns from 326 locations (essentially towns) to decompose property returns into 3 property-types and 11 regions in the UK, using annual data over the period 1981 to 1995 . Using a number of metrics to measure the relative importance of sector and regional factors the author found that sector-specific effects were more than twice as important as regional factors in explaining real estate returns. In a recent study Andrew et al (2003) used the individual property returns from over 12,000 properties to examine the sector and regional effects in the UK, using annual data from 1981 to 2002. Such a large database allowed the authors to examine the impact a finer disaggregation has on the sector and regional effects. Using the HR approach the authors found that the sectorspecific effect had a greater influence on property returns than the regional factors, irrespective the different specifications of sectors and regions. In contrast, Newell and Keng (2003) using the same approach on quarterly data in Australia for 3 sectors and 3 regions the authors found that the pure-regional effect showed marginally greater impact on real estate returns than the sector-specific effect.

This paper extends these studies in two ways. First, it uses a recently constructed database for Italian real estate and so is the first study to examine the relative benefits of sector and regional diversification in Italy. Secondly, in the previous studies regions were defined on a geographical basis rather than by economic function. Previous work, however, has highlighted the shortcomings of defining regions on a geographical basis for portfolio diversification purposes (see Viezer, 2000 and Hamelink et al, 2000 for comprehensive reviews). For example, consider a hypothetical real estate fund that invests in Office property in the City of London and Edinburgh. As Edinburgh is over $600 \mathrm{~km}$ away from the City of London and is the capital of Scotland using the traditional definition of a region, it would appear that the fund is well diversified, as it is invested in widely different geographic locations. The problem, however, is that each of these locations are influenced by the same economic factors and risks and are characterised by the same economic trends and, therefore, would be expected to respond similarly to economic events, in this case the financial services industry. Thus, when we define regions by their economic function the real estate portfolio is not diversified by location in a manner that would significantly reduce overall risk, indeed the risks may be compounded. Thus, when comparing the benefits of geographical and economic 
portfolio diversification researchers have shown that portfolio risk reduction by economic function is more effective than diversification by geographic location. In contrast, a real estate portfolio that is economically diversified will be geographically diversified as well. This study, therefore, is the first paper to test whether economically defined regions are relatively more important than sectors in explaining Italian real estate returns.

Specifically, we distinguish between three kinds of factors. First, a national effect that captures broad co-movement across real estate returns in Italy, in effect controlling for the Italian property cycle. Second a sector-specific factor to capture differences across propertytypes, and third we incorporate a regional-specific effect, which reflects the different economic characteristics of the local real estate markets across Italy.

We use these results to produce a number of statistical criteria against which the relative importance of the sector and regional factors in determining property returns can be assessed. We begin by calculating the absolute average of the sector and regional coefficients, next, we examined the variance of the coefficients and finally the average adjusted R-squared values of the individual impact of the country, sector and regional dummies on property returns.

The remainder of the paper is structured as follows. The next section explains the factor model of Heston and Rouwenhorst (1994). The third section describes the data. Section 4 presents the return performance of the Italian property market. The decomposition of the sector and regional factors is presented in Section 5. Section 6 then discusses the implications of the results for portfolio management. The final section presents the conclusions.

\section{Methodology}

Following Heston and Rouwenhorst (1994) the model assumes that the return on each property depends on three components: a national factor $(\alpha)$, sector factors $(\beta)$ and regional factors $(\gamma)$ and a property-specific disturbance $(\varepsilon)$. Hence, the return on property $i$ that belongs to property-type $\mathrm{j}$ and region $\mathrm{k}$ is given by:

$$
\mathrm{R}_{\mathrm{i}}=\alpha+\sum_{\mathrm{j}=1}^{\mathrm{M}} \beta_{\mathrm{i}, \mathrm{j}} \mathrm{F}_{\mathrm{j}}+\sum_{\mathrm{k}=1}^{\mathrm{L}} \lambda_{\mathrm{i}, \mathrm{k}} \mathrm{F}_{\mathrm{k}}+\varepsilon_{\mathrm{i}}
$$

where:

$$
\begin{array}{lll}
\mathrm{R}_{\mathrm{i}} & =\text { the return of property } \mathrm{i} \text { in time period } \mathrm{t} & \mathrm{i}=1, \ldots . \mathrm{N} \\
\alpha & =\text { the return on the market in general } & \\
\beta_{\mathrm{j}} & =\text { the return to the sector factor } \mathrm{j} & \mathrm{j}=1, \ldots . . \mathrm{M} \\
\lambda_{\mathrm{k}} & =\text { the return to the regional factor } \mathrm{k}=1, \ldots . \mathrm{L} \\
\mathrm{F}_{\mathrm{j}} & =1 \text { if the property is in sector } \mathrm{j}, 0 \text { otherwise. } \\
\mathrm{F}_{\mathrm{k}} & =1 \text { if the property is in region } \mathrm{k}, 0 \text { otherwise }
\end{array}
$$

Equation (1) is a very simple factor model of returns with zero/one exposures to the explanatory variables (sectors and regions) which elegantly allows for the separation of the regional and sector effects, but rules out any interaction between these effects. However, it is not possible to estimate (1) directly by cross-sectional regression techniques, because of perfect multicollinearity between the independent variables. As a result there is no unique way of identifying sector and regional effects. We can only measure cross-sectional 
differences between regions and cross-sectional differences between sectors. One possibility would be to arbitrarily choose one region in one sector as a base, and estimate equation (1) under the restriction that this sector and region are zero. Rather than apply such an arbitrary sector/regional choice, Heston and Rouwenhorst (1994) and Beckers, et al (1996) show that equation 1 can be estimated directly by imposing the following two linear constraints. That is, we find $\alpha, \beta, \lambda$ by minimising the sum of the squared errors $\left(\sum_{i=1}^{N} \hat{\varepsilon}_{i}^{2}\right)$ in equation 1 subject to:

$$
\sum_{i=1}^{N} \sum_{j=1}^{M} \beta_{j} F_{j}=0
$$

and

$$
\sum_{\mathrm{i}=1}^{\mathrm{N}} \sum_{\mathrm{k}=1}^{\mathrm{L}} \lambda_{\mathrm{k}} \mathrm{F}_{\mathrm{k}}=0
$$

As a consequence the intercept term $(\alpha)$ reflects the return on the equal-weighted portfolio of the sampled property across Italy - a benchmark against which sector- and regional-specific effects are measured. Thus, the estimated sector and regional coefficients represent excess returns relative to this return. So for example, if property returns market-wide are mostly positive in general in a given year and Office properties are also rising but less so than the market, then the Office factor return will be negative. The same holds for the regional factors. If property returns are generally positive and North Eastern properties are also rising but by a greater amount than in most other regions, then the North East regional factor return will be positive.

The estimation procedure also allows a decomposition of the actual return of the equally weighted sector or regional portfolio into a number of components of interest. For example, the actual return of a sector property portfolio $R_{j}$ can be decomposed into a national factor common to all regions, $\alpha$, a sector-specific factor, $\beta_{j}$, and the average of the cumulative regional effects of the properties that make up the sector,

$$
\mathrm{R}_{\mathrm{j}}=\hat{\alpha}+\hat{\beta}_{\mathrm{j}}+\frac{1}{\mathrm{~L}_{\mathrm{j}}} \sum_{\mathrm{i}} \sum_{\mathrm{k}=1}^{\mathrm{L}} \hat{\lambda}_{\mathrm{k}} \mathrm{F}_{\mathrm{ik}}
$$

where the i-summation is taken over the properties in region $\mathrm{k}$.

In a similar way the actual return of a regional portfolio $\mathrm{R}_{\mathrm{k}}$ can be broken down into a national factor common to all sectors, $\alpha$. a regional-specific component $\lambda_{k}$, and the average of the cumulative sector-specific effects of the properties that make up the sector,

$$
\mathrm{R}_{\mathrm{k}}=\hat{\alpha}+\frac{1}{\mathrm{M}_{\mathrm{k}}} \sum_{\mathrm{i}} \sum_{\mathrm{j}=1}^{\mathrm{M}} \hat{\beta}_{\mathrm{j}} \mathrm{F}_{\mathrm{ij}}+\hat{\lambda}_{\mathrm{k}}
$$

where the $\mathrm{i}$-summation is taken over the properties in sector $\mathrm{j}$. 
Equation (4) shows that there are two reasons why sector performance can differ from that of the national portfolio. The first is that the regional composition differs across the various sectors. The second is the sector effect, which accounts for differences in the return on properties in sector $\mathrm{j}$ relative to properties in the same region but located, in another sector. The regional factor portfolio can differ from that of an Italian-wide market portfolio for the same two reasons.

Then using these results we follow previous studies in using a number of criteria to evaluate the relative benefits of sector and regional diversification. First, we follow Rouwenhorst (1999) in using the mean absolute deviations (MADs) of the sector $(\beta)$ and regional $(\lambda)$ coefficients from equation (1). We report the equal-weighted average for the sectors and regions to compare the relative importance of the sector and regional effects. The sector MAD can be interpreted as the average tracking error for returns on regional-neutralised sector portfolios relative to returns on the Italian average. The regional MADs have an analogous interpretation. Second the relative importance of the distinct factors can be measured by the time-series volatility of the factor estimates (Heston and Rouwenhorst, 1995). So that if the variance of the sector effects is greater than that of the regional effects, this is indicative of the greater importance of sectors in determining returns during that period. Finally, we follow Beckers et al (1996) and compare the explanatory power of the individual factors, as measured by their adjusted $\mathrm{R}^{2}$ values, in determining property returns relative to that of the full model including all factors. The difference in the cross-section of explanatory power measures the contribution of the omitted variable to explaining individual property returns in a given period $t$.

\section{Data}

In Italy there is a paucity of real estate data available at a national level ${ }^{1}$. There are, however, many local databases of price information for all sectors and some national databases relating to rents and market value, but none of these are provide indices a total return performance. It was, therefore, necessary to take price and revenue information from Nomisma's national database and from this construct an index of income, capital and total returns for the principal property sectors at the city level. This was achieved by collating the information from the quarterly publications produced by $\mathrm{Nomisma}^{2}$, to provided total return information for the years 1989 to 2003. More specifically, the capital growth from May to May of each year was derived from the property market publications. To this was added the corresponding income return from the published information to provide a total return measure for each asset class for 14 Italian cities over the period 1989 to 2003.

The sectors included in the analysis are residential, retail and offices, as these are the main constituents of Italian real estate portfolio. In contrast, industrial property is rarely considered in the asset allocation process of most funds and there was insufficient publicly available information to include this sector in the analysis. The regions of Italy then had to be defined.

\footnotetext{
${ }^{1}$ Recently, Nomisma and the Investment Property Databank (IPD) have created a joint venture to establish a definitive annual index but this is in its infancy having published results only for 2002 and 2003.

${ }^{2}$ Nomisma analyses the property market of the 14 most representative cities in Italy and 13 medium size cities. In this analysis the 14 most important cities were considered.
} 
In the case, economic regions rather than geographical location delineate the areas used in this study, as this is the preferred method of approach in real estate portfolio construction process. The four regions are:

- The North West, characterised by a prominent industrial sector (big industries), whose most important cities are Milano, Torino and Genova;

- The North East, which has benefited from a strong economic cycle, initially in manufacturing and industry (small and medium sized business) but lately in all economic sectors. The cities in this areas are Padova and Venezia, which was divided in Venezia- island and Venezia - Mainland;

- The Centre of Italy, characterised by service-industries and retail sectors. The main cities in this part are Bologna, Firenze and Roma;

- The South and the Islands, where the economy is based mainly on agriculture. The cities in the south are Napoli and Bari, while Cagliari, Catania and Palermo are in the Islands of Sardinia and Sicily.

This four region economic classification of Italy is that which is typically used in studies of the economic regional converge hypothesis (see for example, Mauro and Podrecca, 1994; Paci and Saba, 1998; Terrasi, 1999; and Loenida et al, 2004). In particular, studies show that not only are these four regions economically cohesively but that there as been divergence in economic performance over time rather than convergence in the Barro and Sala-i-Martin (1991) sense, making Italy the most economically regionally diverse country in Europe. Consequently, this analysis provides the first test of the relative benefits of economically regional diversification versus sector diversification in the real estate portfolio. The 4-region by 3 -sector classification scheme also has the advantage that the sector and regional portfolios are about the same size. Thus, we mitigate any potential bias against finding important sector effects induced by more refined regional classifications compared with sector portfolios that are larger and therefore more diversified (see Griffin and Karolyi, 1998).

\section{The Return Performance of Italian Real Estate}

We first discuss the time-series of the coefficients from the cross-sectional regressions using equation 1. Table 1 gives these values for the national factor, the three sectors and four regions and for the individual years from 1989 to 2003. The first row of Table 1 shows the values of the intercept terms $(\alpha)$ from equation 1 and reflects the return on the equalweighted portfolio of the sampled property across Italy. Because equation (1) is estimated year-by-year, $\alpha$ varies over time and so displays the Italian property cycle. As is clear to see the Italian property market followed the performance of most European counties over this period with a boom phase up to 1990 , followed by steady decline until 1994 . The years of the mid 1990s showing small but positive returns, while the start of the new millennium has been one of good returns, although much less than those seen in the late 1980's 
Table 1: National, Regional and Sector Coefficients 1989-2003

\begin{tabular}{|c|c|c|c|c|c|c|c|c|c|c|c|c|c|c|c|}
\hline National, Sector, Region & 1989 & 1990 & 1991 & 1992 & 1993 & 1994 & 1995 & 1996 & 1997 & 1998 & 1999 & 2000 & 2001 & 2002 & 2003 \\
\hline National & 33.48 & 31.39 & 17.96 & 13.46 & 8.40 & -0.16 & 4.76 & 5.41 & 0.01 & 6.13 & 12.78 & 12.65 & 15.58 & 15.21 & 15.27 \\
\hline \multicolumn{16}{|l|}{ Regional Coefficients } \\
\hline North West & 8.07 & 7.57 & 1.18 & -1.26 & -3.83 & -1.38 & -1.84 & -0.22 & -3.80 & -1.99 & -1.55 & -2.44 & -2.23 & -1.22 & -0.89 \\
\hline North East & -1.22 & 0.33 & -2.94 & 0.44 & 4.35 & 3.01 & 4.48 & 1.42 & 4.95 & 2.84 & 5.73 & 2.32 & 1.11 & 1.11 & -0.45 \\
\hline Central & 5.39 & 5.04 & 0.45 & -1.65 & -0.54 & -1.89 & -1.82 & 0.34 & 2.98 & -0.65 & -0.75 & -1.38 & -0.45 & 2.96 & 2.23 \\
\hline South and Islands & -7.34 & -7.76 & 0.79 & 1.48 & 0.01 & 0.16 & -0.50 & -0.93 & -2.48 & -0.11 & -2.06 & 0.90 & 0.94 & -1.71 & -0.53 \\
\hline \multicolumn{16}{|l|}{ Sector Coefficients } \\
\hline Residential & 2.63 & 1.20 & 0.43 & 1.78 & 0.03 & 4.38 & 1.04 & -1.23 & -1.19 & 0.04 & -3.55 & 0.60 & -0.96 & -0.47 & -0.47 \\
\hline Office & -3.35 & -0.89 & 0.49 & -1.54 & 0.11 & -1.65 & -0.03 & -0.04 & 0.88 & -2.48 & 0.01 & -0.70 & -0.59 & -0.65 & -0.82 \\
\hline Retail & -3.35 & -0.31 & -0.93 & -0.23 & -0.15 & -2.73 & -1.00 & 1.26 & 0.31 & 2.44 & 3.53 & 0.10 & 1.56 & 1.11 & 1.30 \\
\hline
\end{tabular}

The next rows of Table 1 show the coefficients of the regional and sector factors. The interpretations of the coefficients are, as outlined above, the impact on property returns of each factor (sector and region) net of a common national effect. For example, the coefficient for the North East in 1989 indicates that investment in an equal weighted portfolio of North Eastern properties under-performed by $1.22 \%$ compared with the equal weighted Italian real estate portfolio in this year. In contrast, in 1995 investment in an equal-weighted North Eastern portfolio out-performed the benchmark average by $4.48 \%$.

In a similar way, if the coefficients of the retail property portfolio are considered it suggests that investment in an equal-weighted portfolio of Residential properties diversified across Italy under-performed by $3.35 \%$ in 1989 , compared with the Italian market in general, and continued to do so until 1996.

These results show that the worst regions to invest in, over this period, would have been North West and the South, which both produced returns significantly below the Italian market average in almost every year. In contrast, returns in the North East out-performed the national average most of the time, while, the best sector to hold over this period would have been residential and the worst offices.

As a final point the coefficients in Table 1 show that the 'best' portfolio to hold in 1989 would have been a portfolio of residential properties, over-weighted in the North West. In contrast, the 'best' portfolio to hold in 2003 would have been invested in retail properties in the Central region. This shift in composition largely reflects cyclical influences specifically the difference in timing of both the business and property cycles across Italy.

\section{The Relative Importance of Sector/Regional Effects}

Table 2 presents the decomposition of the excess sector and regional portfolio returns for the 3-by-4-classification scheme. To determine the relative importance of the sector and regional effects, we examine a number of statistics derived from the cross sectional regressions. First, we calculated the absolute average of the sector and regional regression coefficients. Secondly, we examine the amount of variation explained by the time series of estimated sector and regional coefficients and finally we examined the average R-squared values of the individual impact of the sector and regional dummies on property returns.

Table 2 shows a number of features of interest. First, there is a wide discrepancy in returns across the regions even after controlling for the common national factor and the "pure" sector 
effect. There is a strong positive "pure" regional effect in the North East while the regional effect is negative for the South.

Second, there is considerable cross-sectional variation in the total variances of the regional component. The Central region has the least regional effect variance $\left(5.56^{2}\right)$ closely followed by the North East $\left(5.58^{2}\right)$, with the North West showing by far the largest regional effects $\left(11.82^{2}\right)$. The ratio of these variances to the actual returns of the regions presented in column 4 show that the "pure" regional effects explain all of the variance in the actual returns, while the cumulative sector- explains nothing. This implies that the properties in these four regions are not influenced by any sector considerations.

Table 2: The Decomposition of Italian Excess Property Returns into 4 Regions and 3 Sectors: Annual Returns 1989-2003

\begin{tabular}{lccccc}
\hline & $\begin{array}{c}\text { Mean } \\
\text { Excess } \\
\text { Coefficients }\end{array}$ & $\begin{array}{c}\text { Pure } \\
\text { Regional } \\
\text { Variance }\end{array}$ & $\begin{array}{c}\text { Ratio } \\
\text { Relative to } \\
\text { Actual }\end{array}$ & $\begin{array}{c}\text { Composite } \\
\text { Sector } \\
\text { Variance }\end{array}$ & $\begin{array}{c}\text { Ratio } \\
\text { Relative to } \\
\text { Actual }\end{array}$ \\
\hline Region & -0.39 & 11.82 & 1.00 & 0.00 & 0.00 \\
North West & 1.83 & 5.58 & 1.00 & 0.00 & 0.00 \\
Central & 0.68 & 5.56 & 1.00 & 0.00 & 0.00 \\
South \& Islands & -1.28 & 7.27 & 1.00 & 0.00 & 0.00 \\
\hline Absolute Average & 1.04 & 7.56 & 1.00 & 0.00 & 0.00 \\
\hline & Mean & Pure & Ratio & Composite & Ratio \\
Sector & Excess & Sector & Relative to & Regional & Relative to \\
\hline Residential & Coefficients & Variance & Actual & Variance & Actual \\
Office & 0.28 & 3.20 & 1.13 & 0.23 & 0.07 \\
Retail & -0.75 & 1.19 & 0.89 & 2.22 & 1.87 \\
\hline Absolute Average & 0.19 & 3.04 & 1.00 & 0.00 & 0.00 \\
\hline Regional Adjusted R $\mathbf{R}^{2}$ & $\mathbf{0 . 4 1}$ & 2.48 & 1.01 & 0.82 & 0.65 \\
Sector Adjusted R & $\mathbf{9 . 5}$ & & & & \\
\hline
\end{tabular}

Third, the excess returns of the "pure" sector factor generally show a much lower spread than the regional coefficients. Additionally, all the sectors have sector-specific effect variances are which are considerable below the regional factors, retail properties showing the largest variance $\left(3.04^{2}\right)$ and offices the least $\left(1.19^{2}\right)$. The ratio of the sector-specific variances to the actual returns shows that the "pure" sector factor explains the majority of the variance in the actual returns. However, column 6 of Table 2 shows that there is a regional impact on the sector portfolios, especially for offices, with a cumulative regional impact of $65 \%$.

Next we consider the ratio of all these values to each other as a measure of the relative importance of the each factor to each other (Cavaglia et al, 2000). When we compare the absolute average of the regional coefficients (1.04) to that for the sector coefficients $(0.41)$, we find a ratio of $2.5: 1$. In a similar vein, when we compare the average variance of the regional factors $\left(7.56^{2}\right)$ to the average variance of the sector effects $\left(2.48^{2}\right)$, we find a ratio of $3: 1$. Finally, the adjusted $\mathrm{R}^{2}$ statistics show that the regional effects $(9.5 \%)$ account for more than three times the sector effects $(3.1 \%)$ in determining returns. This implies that regional factors are up to three times more important than sector effects in determining Italian real estate returns. All these results are in contrast to the findings of Fisher and Liang (2000), Lee (2001) and Andrews et al (2003), but provide support of the results of Newell and Keng (2003). This may suggest that regions pay a greater role in determining real estate returns than sector effects in countries that have less mature property markets than the US and UK. 


\section{Implications for Real Estate Portfolio Analysis}

The "pure" factor approach that we have used has important implications for portfolio construction and management. First, the relative size of the sector and regional effects has important implications for risk reduction strategies across sectors and regions and second for the tracking error faced by fund managers.

A pure-sector portfolio assumes that the portfolio has the same regional distribution as the overall benchmark. In other words, a pure-sector portfolio is diversified across the regions. Thus, a large pure-sector variance would indicate that regional diversification is less effective than diversification within a region across the sectors. In a similar vein, a large pure-regional variance would indicate that sector diversification is less effective at risk reduction, as pureregional portfolios are diversified by sector. The results in Table 2 indicate that it is more important to diversify within a sector across the different regions than to diversify within a region across sectors to obtain the largest reduction in portfolio risk. As shown by the fact that the average variance of the pure-regional factor effects is three times larger than the pure-sector-specific effects. This indicates that two properties in the same region are closer substitutes than two properties in the same sector. This is especially the case for offices. Thus, for those fund managers focused on one region it is likely that they will have an undiversified portfolio even if they have holdings in different property-types. In contrast, a fund manager who concentrates on a particular sector, in which he has expertise, can achieve a high level of risk reduction by spreading the fund's holdings across a number of regions.

Fund managers are not only concerned with the overall risk of their portfolios. They are equally, or more, interested in the risk of their portfolio returns relative to some benchmark of performance (Roll 1992). Fund mangers therefore need to be aware of the impact on tracking error from rearranging the composition of the portfolio as a result of sector and regional bets. As shown in Table 2 the pure-regional variances are all greater than the pure-sector variances, thus the tracking errors induced by tilting a portfolio away from the regional composition of the benchmark portfolio will have a greater impact than for sector bets. For instance, suppose an Italian real estate fund manager is considering a sector bet by increasing his weight into offices, or a regional bet as a result of a tilt towards the South. These, two portfolios have approximately the same number of properties. The results from Table 2 indicate that replacing $10 \%$ of the properties in an equal-weighted Italian property portfolio with properties from the office sector would have shown a slight under-performance of $0.075 \%$ per annum, with a tracking error variance of only $1.19^{2}$. In contrast, a $10 \%$ tilt by the fund manager into the South would have led to a significant under-performance portfolio of $0.128 \%$ per annum, with a tracking error variance of $7.27^{2}$. This is a tracking error variance six times greater than that for the sector bet. This suggests that regions defined by economic function, rather than geographic location, provides a greater route to portfolio diversification than sectors

\section{Conclusions}

When investing in real estate portfolio managers often attempt to optimise their asset allocations by sector and location. For the portfolio manager then the question becomes one of investigating whether sector or regional effects are the main drivers of performance and so establish the first level of analysis in portfolio construction and evaluation. The relative benefits of sector and regional diversification have, therefore, been studied in a number of 
countries, but have not previously been investigated in Italy. Additionally, previous studies have used geographically defined regions, rather than economically functional areas, when performing the analysis even though most would argue that it is the economic structure of the area that will lead to differences in demand and hence property performance. This study therefore uses the four economically defined regions of Italy to test the relative benefits of regional diversification versus sector diversification within the Italian real estate portfolio.

To examine this issue we use constrained cross-section regressions the on the sector and regional affiliation of 14 cities in Italy to extract the "pure" return effects of the different factors using annual data over the period 1989 to 2003 . In contrast, to previous studies we find that regional factors effects in Italy have a much greater influence on property returns than sector-specific effects, which is probably a direct result of using the extremely diverse economic regions of Italy rather than arbitrary geographically locations. Be that as it may, the results strongly suggest that that diversification across the regions of Italy used here is likely to offer larger risk reduction benefits than a sector diversification strategy within a region. In other words, fund managers in Italy must monitor the regional composition of their portfolios more closely than its sector allocation. Additionally, the results supports that contemporary position that 'regional areas' based on economic function, provide greater diversification benefits rather than areas defined by geographical location. 


\section{References}

Andrew, M., Devaney, S. and Lee, S. (2003) Another Look at the Relative Benefits of Sectors and Regions in Determining Property Returns, Department of Real Estate and Planning Working Paper, 14/03

Beckers S., Connor, G. and Curds, R. (1996) National Versus Global Influences on Equity Returns. Financial Analysts Journal, 52, 2, March/April, p. 31-39

Cavaglia, S., Brightman, C. and Aked, M. (2000) The Increasing Importance of Industry Factors, Financial Analysts Journal, September/October, 41-54

Fisher, J.D. and Liang, Y. (2000) Is Property-type Diversification More Important than Regional Diversification, Real Estate Finance, 17, 3, 35-40

Grinold R., Rudd, A., and Stefek, D. (1989), Global Factors: Fact or fiction?, Journal of Portfolio Management, 16, 79-88

Hamelink, F., Hoesli, M., Lizieri, C. and MacGregor, B.D. (2000) Homogeneous Commercial Property Markets Groupings and Portfolio Construction in the United Kingdom, Environment and Planning A, 32, 323-344

Heston, S.L. and Rouwenhorst, K.G. (1994) Does Industrial Structure Explain the Benefits of International Diversification? Journal of Financial Economics, 36, 3-27

Heston, S. L. and Rouwenhorst, K.G. (1995) Industry and Country Effects in International Stock Returns, The Journal of Portfolio Management, Spring, 53-58

Kennedy, P, (1986) Interpreting Dummy Variables, Review of Economics and Statistics, 68,174175

Loenida, L., Petraglia, C. and Murillo-Zamorano, L.R. (200) Total Factor Productivity and the Convergence Hypothesis in the Italian Regions, Applied Economic, 36, 2187-2193

Mauro, L. and Podrecca, E. (1994) The Case of Italian Regions: Converge or Dualism?, Economic Notes, 24, 2, 33-78

Morgan, J. (1964) A Note on the Interpretation of Multiple Regression Using Dummy Variables, Survey Research Centre, Institute for Social Research, University of Michigan, April, 28, 2-3

Newell G. and Keng T.Y. (2003) The Significance of Property Sector and Geographical Diversification in Australian Institutional Property Portfolios, Pacific Rim Property Research Journal, 9, 3, 248-264

Paci, R. and Saba, F. (1998) The Empirics of Economic Growth in Italy 1951-1993, Rivistra Internazionale di Scienze Economiche e Sociali, 54, 515-542 
Roll, R. (1992) A Mean/variance Analysis of Tracking Error, Journal of Portfolio Management, Summer, 13-22

Rouwenhorst, G., (1999) European Equity Markets and EMU: Are the Differences Between Countries Slowly Disappearing? Financial Analysts Journal, May-June, 57-64

Suits, D. B. (1984) Dummy Variables: Mechanics Vs Interpretation, Review of Economics and Statistics, 66, p. 177-180

Sweeny, R. and Ulveling, E. (1972) A Transformation for Simplifying the Interpretation of Coefficients of Binary Variables in Regression Analysis, The American Statistician, 26, $30-36$

Terrasi, M. (1999) Convergence and Divergence across Italian Regions, The Annals of Regional Science, 33, 491-510

Viezer, T.W. (2000) Evaluating "Within Real Estate" Diversification Strategies, Journal of Real Estate Portfolio Management, 6, 1, 75-95 